\title{
A comparison between Shear Modulus Degradation Curves
}

\author{
Juan Villacreses ${ }^{1,2}$, Bernardo Caicedo ${ }^{1}$, Silvia Caro ${ }^{1}$, Fabricio Yepez ${ }^{2}$, Lucía López ${ }^{2}$ \\ ${ }^{1}$ Univsersidad de los Andes \\ Cr. 1 \#18a, Bogota, Colombia \\ jp.villacreses@uniandes.edu.co; fyepez@usfq.edu.ec \\ ${ }^{2}$ Universidad San Francisco de Quito \\ Pampite, Quito, Ecuador.
}

\begin{abstract}
The aim of this work is to obtain degradation modulus curves and damping ratio soil dynamic parameters of different plasticity index samples using an AR2000 rheometer at controlled strains, and to show the influence of coupling techniques between samples and the equipment. The shear degradation and damping ratio curves will be obtained in a unique soil test, avoiding the need to combine results coming from other kind of soil dynamic tests such as resonant column and torsional shear tests. Results obtained are compared to the ones obtained with traditional dynamic tests of samples consolidated at the same stress value, in order to validate the experimental results. Comparison demonstrated that this technique permit to obtain accurate results in just one test, for high plasticity index soils. However, for low plasticity soils, results showed a great impact that coupling techniques could have.
\end{abstract}

Keywords: Damping ratio, degradation modulus, rheometer, plasticity index, coupling technique.

\section{Introduction}

Soil dynamic behavior is one of the key factors to take into account, in order to understand and to predict seismic behavior of structures. When there is a cyclic load, such as earthquakes, soil acts as another kind of structure and dissipates energy. This energy dissipation depends on the damping coefficient [1]. Damping is a measure of the dissipated energy due to vibration or cyclic loadings. This energy loss often occurs in the form of heat [2]. Another dynamic soil property that is critical in the soil response is the shear modulus that degrades with strong cycles [3]. Experimental methods that are commonly used to measure these soil properties are resonant column and torsional shear equipment tests. Through these methods, it is possible to obtain soil degradation curves within a wide range of strains (using the resonant column for low strain levels and the torsional shear test for larger strains). The results of both techniques are then combined to obtain the total degradation curve.

Nevertheless, the fact that different techniques are used to construct a single curve creates doubts on the reliability of the resulting degradation curves [4]. A possibility to obtain shear modulus and damping ratio curves in a unique soil test using a rheometer is the aim of this study. Results of two fine-grained soil sample curves completed with a dynamic shear rheometer will be compared with those obtained in the literature. This comparison is carried out to verify the effectiveness of the measuring method.

\section{Equations}

The dynamic shear modulus and phase angle were obtained experimentally for these calculations by using a rheometer. The phase angle is the lag between deformation and applied torque. To carry out the data processing and the comparison between the experimental test and literature, the following equations were used.

Damping ratio was calculated with equation (1) provided by Kelly [5] as the ratio of dissipated energy and elastic stored energy.

$$
D=\tan \left(\frac{\delta}{2}\right)
$$

Where:

$\mathrm{D}$ is the Damping ratio.

$\delta$ is the phase angle in degrees. 
The experimental values of degradation modulus were normalized by using equation (2)

$$
\text { Normalized } G=\frac{G}{G_{\max }}
$$

Where:

$\mathrm{G}$ is the shear modulus of the sample obtained with the rheometer at different strains.

$\mathrm{G}_{\max }$ is the maximum experimental value of the shear modulus.

\section{Materials}

Two soil samples were fabricated in order to analyze the influence of coupling agent in the measuring of soil shear modulus degradation curve. The samples were constructed using two types of soils (i.e. Kaolin and Bentonite). These soils were mixed in different proportions to obtain samples with different index properties. The first sample was $100 \%$ Kaolin with a liquid limit of $86 \%$ and plastic limit of $31 \%$, resulting in a plasticity index of 55 . The second sample was $48 \%$ Kaolin and 52\% Bentonite. This sample has a liquid limit of $202 \%$ and a plastic limit of $20 \%$ resulting in a plasticity index of 182 . Soil index properties were determined according to ASTM D4318-84 [6]. Additionally, specific gravity of the soil mixtures was determined [7]. The measured values of soil specific gravity for soil mixtures are 2.54 and 2.61 for Sample1 and Sample2, respectively. Properties are summarized in Table 1.

Table 1: Samples' properties.

\begin{tabular}{|c|c|c|c|c|c|c|}
\cline { 2 - 7 } \multicolumn{1}{c|}{} & \multicolumn{2}{c|}{ Content } & \multicolumn{2}{c|}{} \\
\hline Sample & $\begin{array}{c}\text { Kaolin } \\
(\%)\end{array}$ & $\begin{array}{c}\text { Bentonite } \\
(\%)\end{array}$ & $\begin{array}{c}\text { Liquid } \\
\text { limit } \\
(\%)\end{array}$ & $\begin{array}{c}\text { Plastic } \\
\text { limit } \\
(\%)\end{array}$ & $\begin{array}{c}\text { Plasticity } \\
\text { index }\end{array}$ & $\begin{array}{c}\text { Specific } \\
\text { gravity }\end{array}$ \\
\hline 1 & 100 & - & 86 & 31 & 55 & 2,54 \\
\hline 2 & 48 & 52 & 202 & 20 & 182 & 2,61 \\
\hline
\end{tabular}

\section{Equipment}

A special cylindrical mold was built for the preparation of the soil samples. It consists of two main parts. The first part is a cylinder with acrylic walls and a stainless-steel base. In this element, water is poured to saturate the soil sample for the consolidation process. The second part is a stainless-steel cylinder with a teflon coating in the inside to avoid any friction stress that can affect the sample. The soil is poured in this second element for consolidation. The dimensions of the mold are summarized in Figure 1. The diameter of the acrylic container is $107.02 \mathrm{~mm}$, and the separation between hole screws inside is $60.23 \mathrm{~mm}$. It can be seen in Figure $1 \mathrm{a}$ ) and b). The piston (i.e. Figure $1 \mathrm{c}$ )) has a length of $107.39 \mathrm{~mm}$ and radius of 12.95 $\mathrm{mm}$, and the mold with Teflon coating shown in Figure $1 \mathrm{~d}$ ) has an inside diameter of $12.95 \mathrm{~mm}$. 

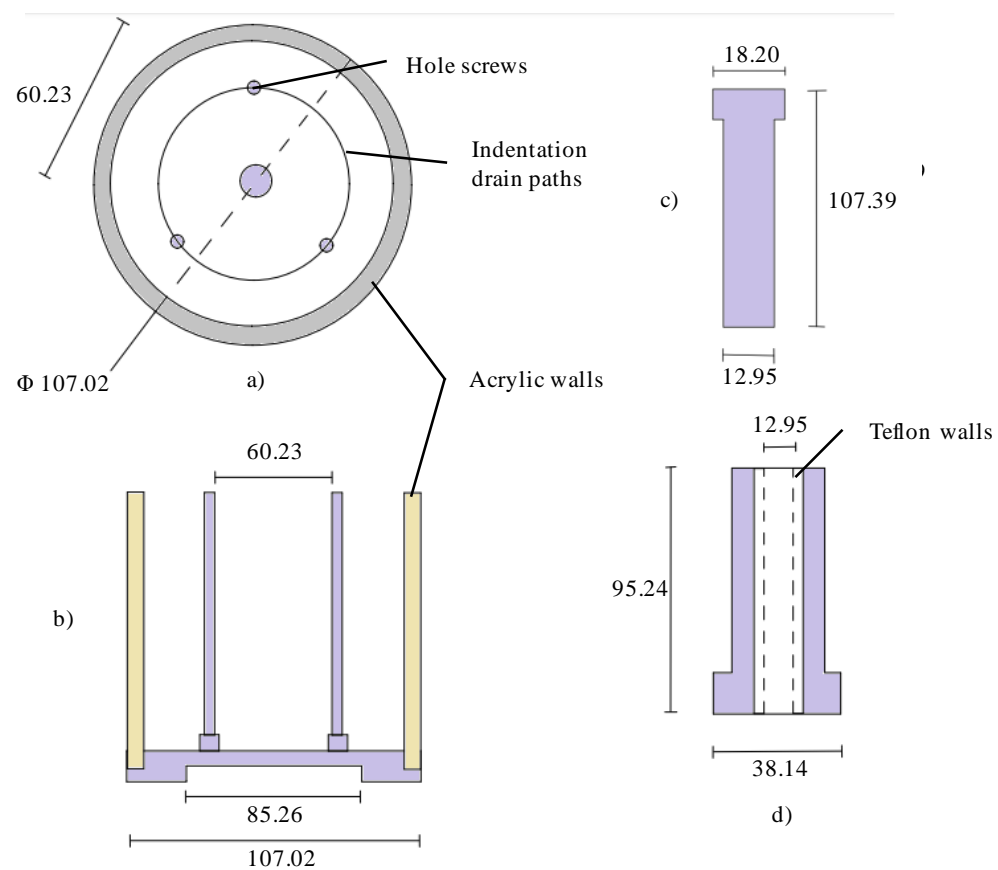

Fig. 1: Sample preparation mold: a) acrylic container plan view and b) lateral view, c) piston and d) mold.

The consolidation process took place in a conventional oedometer. The used equipment corresponds to ASTM D2435 M-11 [8]. The load was incremented until the samples reach a consolidation stress of $100 \mathrm{kPa}$. A piston was built to load the samples and to remove them from the mold. One end of the piston was enlarged to ensure a proper load transfer between the odometer and the piston.

A rheometer was used to measure shear modulus for a range of strains[9]. In this study the AR 2000 was used [10]. The main specifications of the apparatus are: torque range that goes from $0.1 \mu \mathrm{N} . \mathrm{m}$ to $200 \mathrm{mN}$.m , its frequency range goes from $7.5 \times 10^{-7}-628 \mathrm{rad} / \mathrm{s}$, and the equipment is able to test solid samples [10]. The coupling devices were modified and adapted to test cylindrical solid samples.

\section{Procedure}

The procedure seeks to study the influence of the coupling technique between the sample and the equipment on determining the degradation modulus over a range of strains. To achieve this objective, two soil samples were made with a controlled plasticity index. The soils used for sample fabrication were mixed with water at 1.8 times their Liquid Limit. Then, the samples were consolidated within a sequence of loads that produced stresses of 10,20,40,80,100 kPa in a lapse of two days. The end of the consolidation was monitored using Taylor Square root of time [11]. The samples' heights were 46.03 $\mathrm{mm}$ and $40.75 \mathrm{~mm}$ for samples 1 and 2, respectively. The sample diameter was kept constant to $12.95 \mathrm{~mm}$ because of the fixed teflon coating.

The samples were tested in the AR 2000 rheometer to obtain the degradation moduli curve. The experimental measurements were compared to the results obtained by Vucetic [12]. The used test was a strain controlled procedure, where the torque for each strain steep was recorded. The test begun with a strain of $5 \times 10^{-6}$, computed as conventional torsional procedures (i.e. ratio of deformation arc length by the height of the sample). The strain was twice the previous one until reaching a deformation of $2 \times 10^{-2}$. The frequency of the strain deformation was $1 \mathrm{~Hz}$ throughout the test.

\section{Results}

The experimental results and the data taken from Vucetic [12] are shown in Figures 2 and 3. 


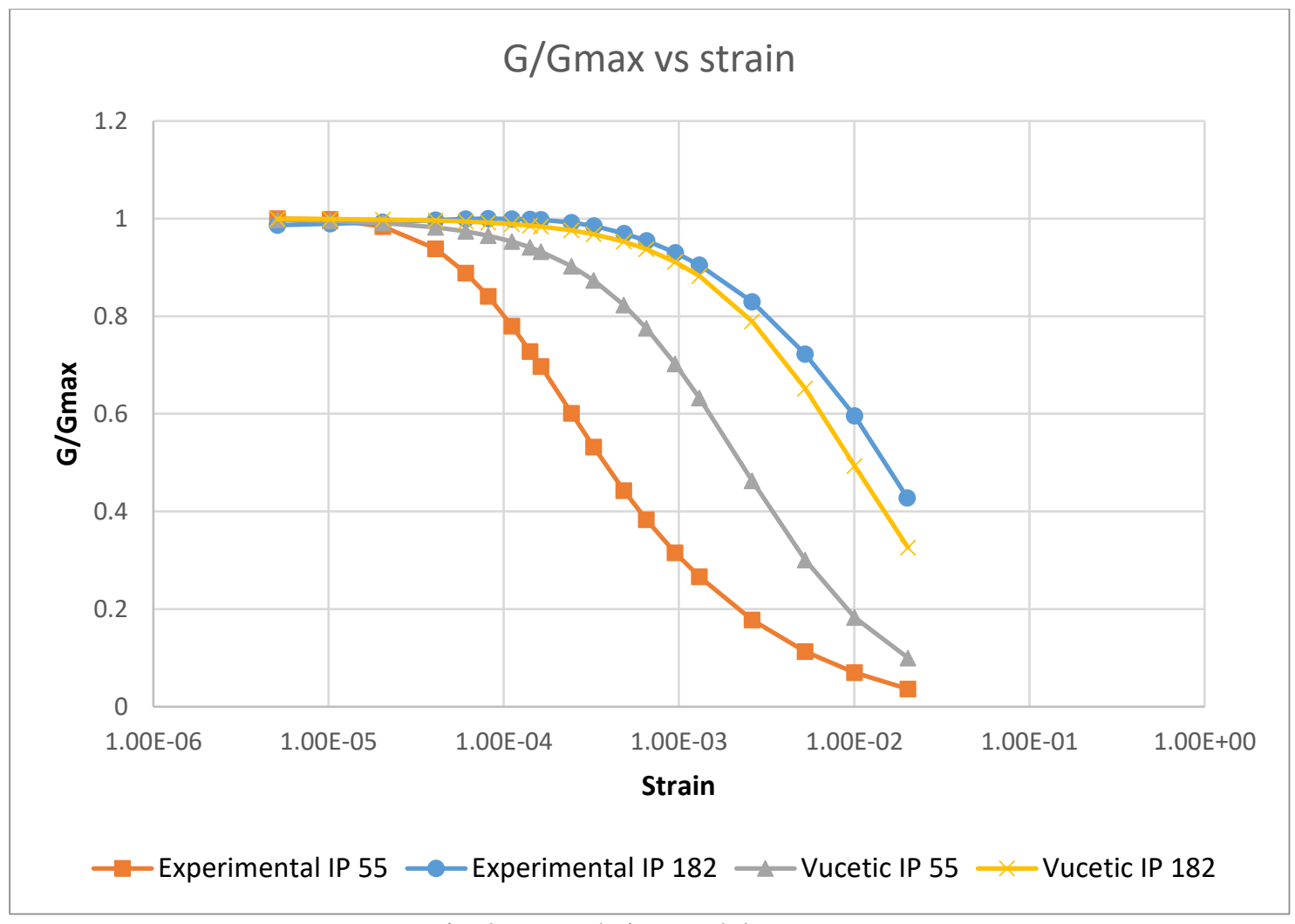

Fig. 2: Degradation modulus curves.

Figure 2 shows the normalized degradation modulus curve of both, experimental samples tested with the rheometer and the degradation modulus curves found in literature [12]. The figure shows that the beginning of the material degradation for the sample with plasticity index of 182 is found at a strain value of $2 \times 10^{-4}$. This strain value matches the theoretical results [12]. On the other hand, for the sample with plasticity index of 55, the experimental data shows that the material degradation begins at a strain of $2 \times 10^{-5}$, while reference data show it begins at $4 \times 10^{-5}$ [12]. These numbers suggest that for low plasticity index, the adhesion quality between the sample and the testing instrument influences the start of the degradation of the material.

For samples with high plasticity index, the percentage difference between the experimental data and literature results is less than $5.0 \%$ at strains below $1 \times 10^{-3}$. Percentage difference at strains greater than $1 \times 10^{-3}$ increased significantly up to $31.3 \%$ at a strain of $2 \times 10^{-2}$. On the contrary, for samples with lower plasticity index, percentage differences exceed $10.0 \%$ at strains of $8 \times 10^{-5}$, and they reach a percentage difference of $63.6 \%$ at the maximum strain. 


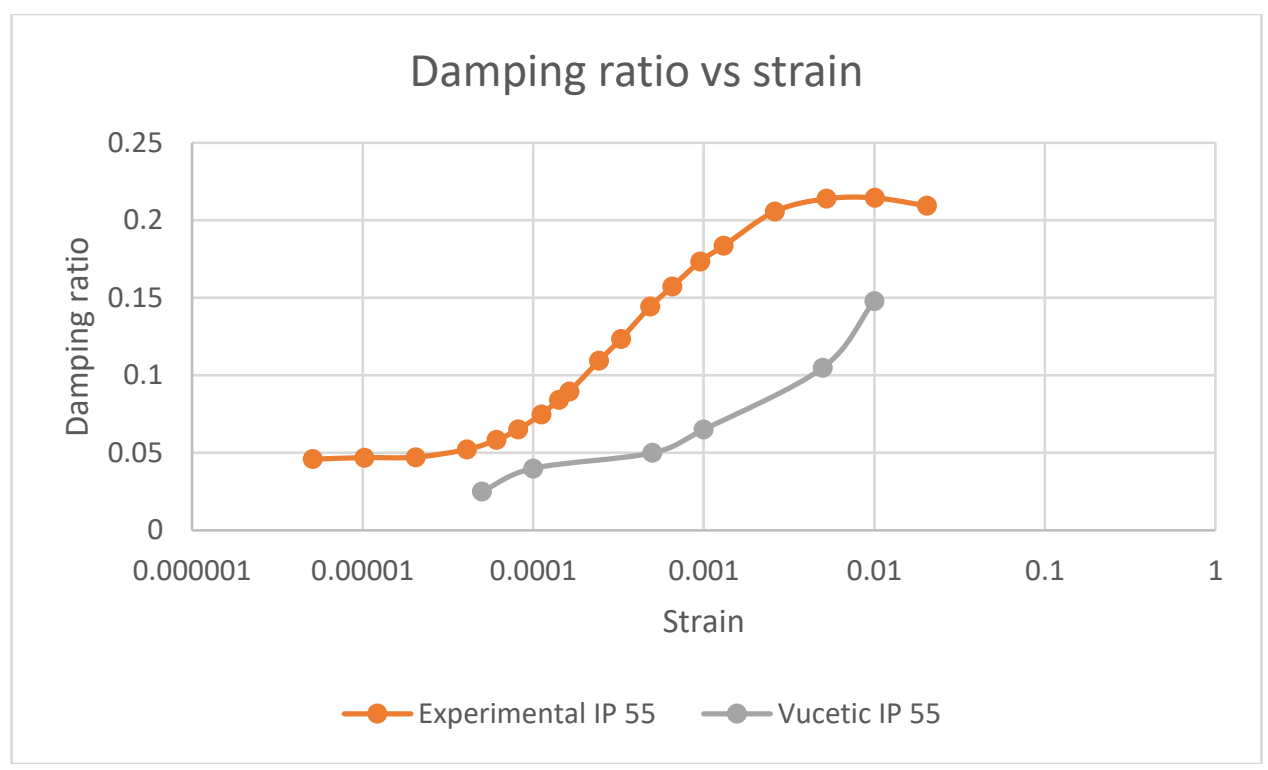

(a)

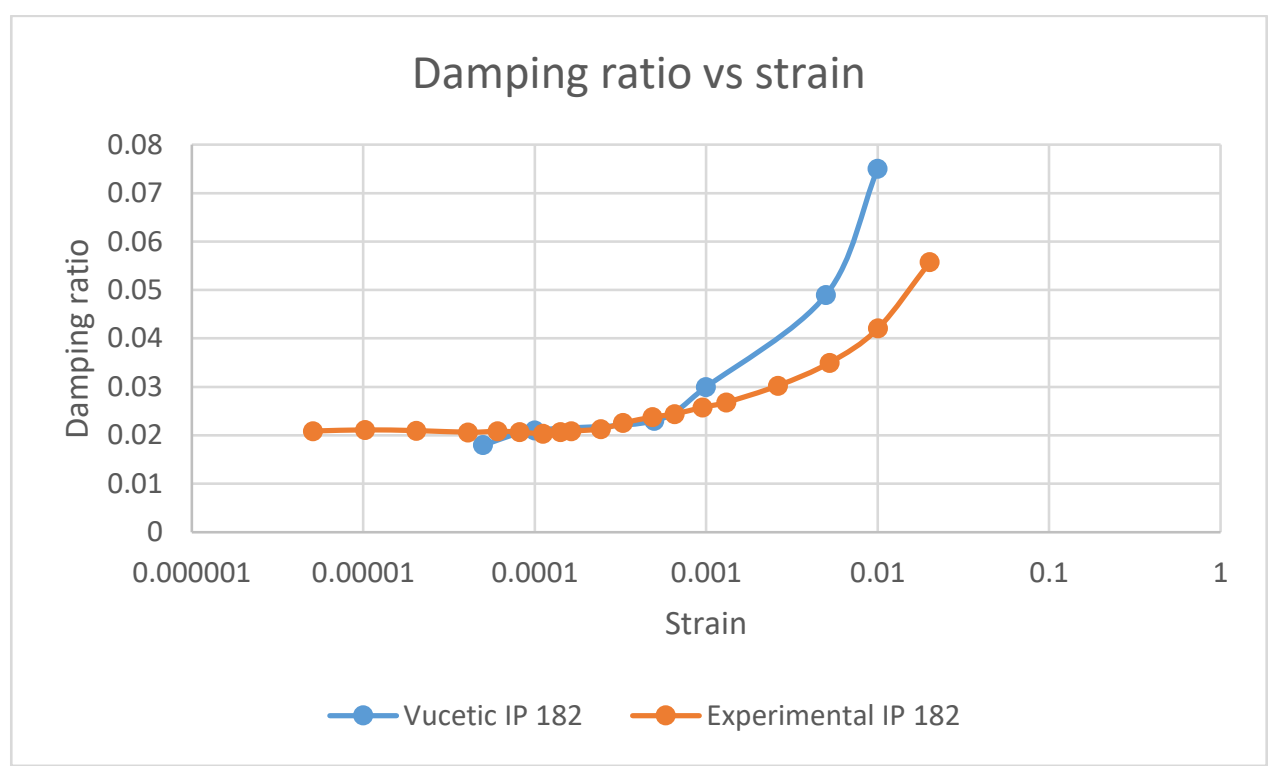

(b)

Fig. 3: Damping ratio for (a) plasticity index 55 soil sample and (b) plasticity index 182 soil sample.

Figure 3 contains the data of damping ratio of the two samples compared to the theoretical information [12]. Figure 3(a) presents the results of sample 1, and it shows an evident difference between the results obtained in the test and the ones given by the bibliographic reference [12]. Picornell [13] explains the influence of the coupling techniques in these measurements when samples are tested on the torsional Resonant Column. This can be the reason for the discrepancy between the experimental results and theory [12]. A different outcome is observed in the sample with a higher plasticity index. In this case, the difference between the test results and the theoretical ones [12] at low damping ratio is minimal, and it increases with the increasing values of damping.

\section{Conclusions}

This paper presents the degradation modulus curves and damping ratio of two soil samples of kaolin and bentonite with different plasticity index (i.e. 55 and 182). These samples were consolidated at the same stress by using an oedometer and a 
special mold built with stainless steel and teflon. They were tested in the AR 2000 rheometer, and the resulting data was compared to the information found in professional literature [12]. The graphs showing the degradation modulus and damping ratio suggest that the coupling technique influences the measurements of the samples. Figures show that the role that the coupling technique plays in these measurements affects more in samples with low plasticity index. The beginning of plastification in the sample with low plasticity index is different between the experimental results and the reference data [12], and the percentage difference at different strains is higher for this sample than it is for the high plasticity index sample. The results obtained from this test support the conclusions described in literature [13], who compares various coupling techniques and demonstrates its influence in damping measurements.

\section{References}

[1] M. Lin, S. Ni, S. Wright, \& K. Stokoe, "Characterization of material damping in soil. III," Ninth world conference on earthquake engineering, Tokyo-Kyoto, Japan, 1988.

[2] A. K. Ashmawy, R. Salgado, S. Guha, and V. P. Drnevich, "Soil Damping and Its Use in Dynamic Analyses," International Conferences on Recent Advances in Geotechnical Earthquake Engineering and Soil Dynamics, 1995.

[3] B. Hardin and V. Drnevich, "Shear modulus and damping in soils: Design equations and curves," Journal of the soil mechanics and foundations division, Proceedings of the American Society of Civil Engineers, 1972.

[4] M. Karray, M. Hussien, M. Chekired \& Y. Ethier, "Small strain stiffness and stiffness degradation curve of sensitive Champlain clay," 2016.

[5] P. Kelly, "Solid mechanics part I: An introduction to solid mechanics," 2013.

[6] ASTM D4318-84. (1984). Standard Test Methods for Liquid Limit, Plastic Limit, and Plasticity Index of Soils

[7] ASTM D854-14. (2014). Standard Test Methods for Specific Gravity of Soil Solids by Water Pycnometer.

[8] ASTM D 2435 M-11. (2011). Standard Test Methods for One-Dimensional Consolidation Properties of Soils Using Incremental Loading

[9] J. P. Villacreses, B. Caicedo, S. Caro, F. Yépez, "A novel procedure to determine shear dynamic modulus and damping ratio for partial saturated compacted fine-grained soils," in Soil Dynamics and Earthquake Engineering, 2020.

[10] TA Instruments. (2007). AR 2000 Rheometer Rheometrics Series Operator's Manual, (January).

[11] D. W. Taylor, Fundamentals of Soil Mechanics. John Wiley and Sons, New York, 1948.

[12] M. Vucetic and R. Dobry, "Effect of soil plasticity on cyclic response," Journal of Geotechnical Engineering, vol. 117, no. 1, pp. 89-107, 1991.

[13] M. Picornell, S. Nazarian \& A. Y. Almadhoun, "Effect of specimen coupling on the torsional Resonant Column test," Geotechnical Testing Journal, vol. 36, no. 4, pp. 476-483, 2013. 